\section{Squamous cell \\ carcinoma occurring in the wall of a chronic aspergilloma}

\author{
S M Andrew, M Bhattacharjee, \\ D J M Keenan, H Reid
}

\begin{abstract}
An aspergilloma that occurred within an area of bronchiectasis in a 52 year old man persisted for 12 years despite medical and surgical treatment. A squamous cell carcinoma developed in the wall of the cavity.
\end{abstract}

Pulmonary carcinoma is occasionally followed by invasion of the lung by Aspergillus. ${ }^{1-5} \mathrm{We}$ report a case where there was good evidence that an aspergilloma preceded the carcinoma.

\section{Case report}

A 64 year old man underwent an elective pneumonectomy for an apparent recurrence of an aspergilloma in his bronchiectatic left lung.

The patient's problems had started in 1974 when he underwent gastric surgery. This was complicated by a left subdiaphragmatic abscess and empyema. The empyema proved resistant to treatment and he was left with a bronchopleural fistula and bronchiectasis, which persisted despite repeated surgical interventions. In 1978 a routine wound swab grew Aspergillus fumigatus and there was radiographic evidence of an aspergilloma in the bronchiectatic left lung. Over the ensuing years he required several blood transfusions for recurrent haemoptysis. In 1986 thoracoscopic removal of the aspergilloma was performed and the haemoptysis settled. In October 1989 the haemoptysis recurred and his serum aspergillus precipitins were found to be considerably increased. He also developed severe left sided chest pain for the first time and in March 1990 it was decided to remove the left lung. At operation the pleural cavity at the apex of the left lung was found to be obliterated by fibrous adhesions; the lung was dissected from the chest wall. Postoperatively the patient recovered well but his pain persisted. He was discharged home, where he died five months later. Necropsy was not performed.

Pathological findings The pneumonectomy specimen showed substantial bronchiectasis (figure). The largest cavities were in the apex of the lung. Between the wall of the largest cavity and the apical pleura was an area of white fibrous tissue, which on histological examination was found to consist of a well differentiated squamous cell carcinoma; local- isation of the carcinoma to the wall of the cavity was confirmed and no carcinoma or dysplasia was found in bronchi away from the area. The tumour had invaded the pleura up to the apical excision margin, suggesting that the patient's chest pain was due to local invasion of the chest wall. Within the cavity there were balls of septate branching hyphae typical of aspergillus in an aspergilloma. There was no evidence of invasion by the fungus.

\section{Discussion}

Aspergillosis is a well recognised but rare complication of pulmonary carcinoma and the differential diagnosis of a cavitating apical lesion may be difficult; ${ }^{1-5}$ several histological types of tumour have been associated with aspergillus infection. There has been no evidence, however, that the aspergilloma preceded the tumour in any of the reported 'cases. In our case there can be no doubt that the patient had a chronic longstanding aspergilloma.

It has been shown in animal models that Aspergillus species have carcinogenic properties, particularly in association with pulmonary adenocarcinoma. ${ }^{6-7}$ Moreover, the association between ingestion of aspergillus toxin and hepatocellular carcinoma ${ }^{8}$ in man is well recognised $^{8}$; this probably results from synergy between a viral infection (hepatitis B) and Aspergillus flavus toxin in the diet. Our

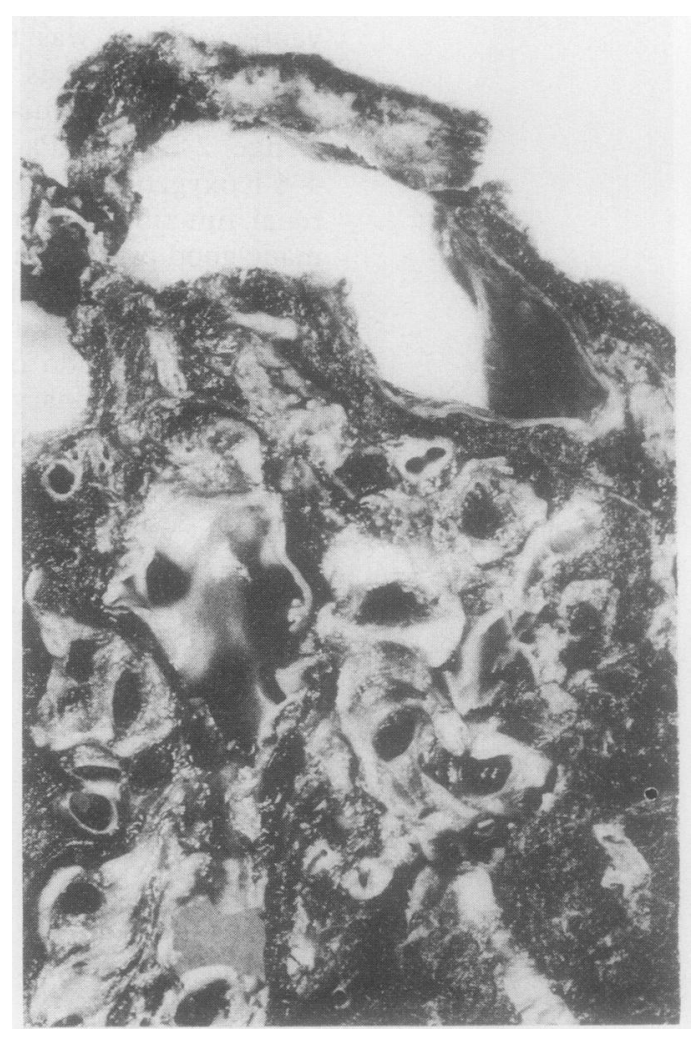

Apex of the left lung showing pronounced bronchiectasis with a large apical cavity. The wall of the large cavity shows white fibrous thickening immediately below the apical pleura. When examined microscopically the area of thickening proved to be invasive squamous cell carcinoma. 
patient was not known to have had any virus infection and did not smoke.

The patient did have a chronic bronchopulmonary fistula and presumably associated scarring. Although fistulas and bronchiectasis are not associated with pulmonary neoplasia, scarring is associated with adenocarcinoma, possibly as a result of the tumorigenic properties of desmoplasia. ${ }^{9}$ No such association has been described with squamous cell carcinoma, however, so the tumour may have been induced by the unusually long persistence of the fungus in the lung.

1 Mays EE, Hawkins JA. Cavitary bronchiolar carcinoma with an intracavity aspergilloma. Am Rev Respir Dis 1967 95:1056-60.
2 Monie RDH. Invasion of a bronchial carcinoma by Aspergillus fumigatus. Thorax 1978;33:660-1.

3 Torpoco JR, Yousuffidin M, Pate JW. Aspergilloma within a malignant pulmonary cavity. Chest 1976;69:561-3.

4 Warembourg H, Ribet M, Lekieffre J, Bertrand M, Damaille A, Houke M. Aspergillome developpé dans un cancer bronchiolaire excavé. Lille Med 1965;10:176-8.

5 McGreggor DH, Papasian CJ, Pierce CD. Aspergilloma within a cavitating pulmonary adenocarcinoma. Am J Clin Pathol 1988;91:100-3.

6 Blyth W, Hardy JC. Mutagenic and tumourigenic properties of the spores of Aspergillus clavatus. Br J Cancer 1982; of the spores

7 Wong FR, Zhong ZD, Jiao B, Wong Z. Experimental studies of lung adenocarcinoma in mice induced by corn flour inoculated with Aspergillus flavus [in Chinese]. Chung Hua Chung Liu Tsa 1981;3:91-3.

8 Patten RC. Aflatoxins and disease. Am J Trop Med Hyg 1981;30:422-39.

9 Barsky SH, Huang SJ, Bhuta S. The extracellular matrix of pulmonary scar carcinomas is suggestive of a scar origin. Am J Pathol 1986;124:412-9.

\section{BOOK NOTICE}

All books reviewed here are available from the BMJ Bookshop, PO Box 295, London WC1H 9TE. Prices include postage in the UK and for members of the British Forces Overseas, but overseas customers should add $£ 2$ per item for postage and packing. Payment can be made by cheque in sterling drawn on a UK bank, or by credit card (Mastercard, Visa, or American Express; give card number, expiry date, and full name).
The Social Impact of Asthma. Andrew Nocon, Tim Booth. (Pp 81; £6.) Sheffield: Centre for Primary Care Research, 1990. ISBN 0-907-484-14-X.

This small monograph addresses important questions about "the social impact of asthma on sufferers and their families." It is in three sections. The first is a most valuable review of published reports, which reveals evidence for an important impact of asthma on work (and school), social life, emotional wellbeing, and economics. There then follow two chapters giving the results and analysis of a survey by questionnaire of a group of asthmatic patients. Areas covered included general activities, changes made in the home, schooling, work, effects on carers, finances, and emotional impact. The weakness of this section is the chosen base and the number of individuals studied. The choice of patients who had been admitted to hospital with asthma admittedly focuses attention on those with more severe asthma but as a consequence does not give a balanced overview of the social impact of this common disease as most asthmatics do not get admitted to hospital. With regard to numbers, a random sample of 60 subjects was drawn from 484 patients admitted to hospital during four months. In the end only 50 sets of results were available for analysis, so there is no way in which any valid statistical conclusion can be drawn. Fortunately the conclusions that the authors do gather together in their final section are broad and sensible, pointing to useful avenues to follow in the future.-DJL 